Anara Sandygulova*, Zhanel Zhexenova, Bolat Tleubayev, Aidana Nurakhmetova, Dana Zhumabekova, Ilyas Assylgali, Yerzhan Rzagaliyev, and Aliya Zhakenova

\title{
Interaction design and methodology of robot-assisted therapy for children with severe ASD and ADHD
}

https://doi.org/10.1515/pjbr-2019-0027

Received May 10, 2019; accepted August 30, 2019

\begin{abstract}
This paper presents a patient-centered interaction design of Robot-Assisted Therapy or Robot-Assisted Play (RAP) applications for children with a diverse form of Autism Spectrum Disorder (ASD) combined with Attention Deficit Hyperactivity Disorder (ADHD). Through our iterative evaluation process based on observations of fourteen children over several sessions and interviews with their parents, we continuously refined the behaviors of a humanoid robot NAO that are now ready to be used for research on Robot-Assisted Therapy. This paper also reports the design of RAP methodology that might be helpful in assimilating iterative input from stakeholders such as children, parents and therapists to customize technology for other populations with special needs.
\end{abstract}

Keywords: Robot-Assisted Therapy, Robot-Assisted Play, Robot-Enhanced Therapy, Robot-Mediated Therapy, Autism Spectrum Disorder (ASD), Attention Deficit Hyperactivity Disorder (ADHD)

\section{Introduction}

A number of recent large-scale interdisciplinary projects, such as DREAM [1], AuRoRa [2] and SAR [3], have explored

\footnotetext{
*Corresponding Author: Anara Sandygulova: Department of Robotics, Nazarbayev University, Kabanbay Batyr Avenue, 53, Nur-Sultan, Kazakhstan, Email: anara.sandygulova@nu.edu.kz Zhanel Zhexenova, Bolat Tleubayev, Ilyas Assylgali, Yerzhan Rzagaliyev: Department of Robotics, Nazarbayev University, Kabanbay Batyr Avenue, 53, Nur-Sultan, Kazakhstan Aidana Nurakhmetova, Dana Zhumabekova: Department of Computer Science, Nazarbayev University, Kabanbay Batyr Avenue, 53, Nur-Sultan, Kazakhstan

Aliya Zhakenova: Republican Children's Rehabilitation Center, University Medical Center, Turan Avenue, 36, Nur-Sultan, Kazakhstan
}

child-centered research by advancing social robots through development and experimentation to suit the needs and challenges of children with social and cognitive deficits.

A critical review by Diehl et al. [4] examined empirically based evidence on the clinical applications of robots in treatment of Autism Spectrum Disorders (ASD) and concluded that most studies are exploratory and have methodological limitations that make it difficult to draw firm conclusions about the clinical utility of robots, e.g. [5].

This research is motivated by the challenges of conducting generalizable research considering diverse forms of ASD and ADHD. Due to a large spectrum of individual nuances, heterogeneous behavioral issues and conditions present in ASD and ADHD children, this ongoing research aims to customize research processes for them. With a goal of a large-scale deployment of RAP as an additional kind of therapy, this research aims for autonomy and generalization at the same time. To this end, this paper reports two phases of our iterative interaction design that were conducted with a two-fold purpose: 1) to evaluate robotic applications, and, mainly, 2) to evaluate the proposed methodology for the RAP research. Once there is a clear and rigorous methodology with reliable and fastto-deploy robots, this methodology could then be used to investigate whether RAP is effective for ASD children with statistically supported evidences.

This paper presents the first outcome of this research project - robotic applications. First, we utilized an interaction design process conducted with the aim to design appropriate robot behaviors tailored for the diverse forms of ASD and ADHD in children. For this process, we conducted an iterative approach with fourteen children (via two complete phases) who met with the robot on several occasions for a 15-minute session. Qualitative data was collected via observations and semi-structured interviews with their parents. Both parents and therapists contributed with establishing requirements needed to address individual differences and provided feedback and suggestions for the improvement of the applications. 
In addition, this paper reports two interaction design life cycles of the proposed RAP methodology that included various stakeholders within the process. The contributions of this paper are in detailed discussions of the technical and ethical issues encountered in the process. Giving the difficult nature of such research, this paper contributes with its guidelines, report of recruitment procedure, qualitative descriptions of how ASD children of diverse forms responded to the implemented robot's behaviors and suggestions for various ways different approaches/activities could be effective or ineffective with severe ASD children.

To this end, we surveyed the literature on RAP for ASD in order to find ideas for the behaviors, implemented new behaviors and utilized off-the-shelf applications that were fine-tuned from session to session. The data suggests that most children enjoyed interactions with the robot, and some even had noticeable improvements. The findings of whether RAP is effective for ASD children are still inconclusive due to a small sample size and a need for quantitative data. However, this paper contributes with its methodology on how to conduct such research, establishes background and sets the needed requirements and motivation for further research that will involve more participants.

Section II discusses related works. Section III describes our interaction design process. Section IV provides description of the first phase of the RAP research methodology that was improved and repeated in the second phase detailed in Section V. The paper concludes with Discussion and Conclusion sections in Sections VI and VII respectively.

\section{Related work}

Although Robot-Assisted Therapy intervention into treatment of ASD has demonstrated noticeable success $[1,2]$, practical deployment of these technologies tailored for the diverse form of autism combined with ADHD is still in its infancy.

The AuRoRA (Autonomous Robotic platform as a Remedial tool for children with Autism) project, one of the earliest works that incorporated a social robot into the therapy of autism in children, was introduced by Dautenhahn [2]. The concept of this project is to create an environment that allows the child to interpret repetitive actions by using a robot. It is hypothesized that a child feels more relaxed and motivated to interact with a robot due to its simplicity and repetitive actions. To this end, the KASPAR robot was designed and evaluated in various settings and scenarios ranging from one time encounters to long-term studies.

Wood et al. [6] presented a methodology to assist children with ASD to develop their Visual Perspective Taking (VPT) skills using the humanoid KASPAR robot. They contribute to the development of pre- and post- assessments to measure children's progress and also inclusion criteria to be used for participants' recruitment. Among 12 participating children aged 11-14 years old the VPT games with KASPAR were the most beneficial to children with the moderate and high level (ADOS $>6$ out 10) of autism.

Within the DREAM (Development of Robot-Enhanced therapy for children with AutisM spectrum disorders) project, the main objective was to develop a supervised autonomy of Robot-Enhanced Therapy (RET) in order to provide a consistent therapy experience and to lighten the burden on human therapists who otherwise have to remain in control of the robot and the therapy [7]. To this end, a robotic setup consisted of a robot, a 26-in capacitive touchscreen (optional), and an intervention table to capture sensory information by employing three RGB cameras and two Kinect sensors. As stated by the authors, the technical requirements were too complex to be beneficial for most end users [7]. Nevertheless, they conducted a study with 5 children with ASD who received 20 intervention sessions (8 RET sessions, 8 standard human sessions, and 4 sessions with the intervention that was more effective for each particular child). The results were statistically analyzed in single-subject experiment based on turn-taking performance and eye gaze. The findings were that the RET was as good as human-mediated therapy, but RET seemed to be more interesting as children looked more at the robot compared to the human partner. However, the reason for the increase in eye gaze time during RET sessions may be due to the novelty of the robot [8].

As the initial DREAM setup was too complex, a lighter version of the system was then proposed, Dream Lite, that only consisted of a tablet and a robot [9]. It included applications targeted at improving imitation, turn-taking and joint attention. Dream Lite was validated in 10 clinical institutions in Romania with a total of 67 children with an ASD diagnosis or ASD symptoms. The interventions consisted of five sessions: a behavioral assessment based on Autism Diagnostic Observational Schedule (ADOS-2) [10], three 30-minutes intervention sessions with the robot, and a final evaluation based on ADOS-2. The children were then compared to the control condition where children followed regular education activities for two weeks.

Kim et al. [11] conducted an experiment with 24 children (aged 4.6-12.8 years old) diagnosed with a highfunctioning autism who interacted with three partners (a 
human, a social dinosaur robot and a touchscreen computer game) and a human facilitator in three 6-min sessions. As a result, children spoke more to the facilitator during interaction with the robot, while the computer game was less effective than two other conditions in eliciting speech.

The study conducted by Boccanfuso et al. [12] reported that although their only nonverbal participant (out of six participants) did not make any significant gains in communication or speech, some fundamental imitation and attention skills were improved throughout a 6-week robotassisted intervention with a low-cost kinematically simple Charlie robot.

Tapus et al. [13] investigated whether autistic children show more social engagement towards the NAO robot or to a human partner in a motor imitation task via conducting four single-subject experiments. Three children with a moderate level of autism and one child with a severe form aged from 2-6 years participated in a 4-week study with two intervention sessions per day (one dyadic with either a robot or a human and another triadic with either a robot or a human and the experimenter). Results were mixed and showed that the level of the autism affected the results, since the child with a severe form rejected participation in the sessions with the human. Overall, they suggest that interaction with the NAO robot is more attractive and useful for children with a low-functioning autism.

The main focus of the Srinivasan et al. [14] work was to analyze the effects and consequences of three types of intervention (rhythm, robotic and standard-of-care) on children with ASD (confirmed by ADOS-2). The experiment with 36 participants (5-12 years) had 32 sessions, four sessions per week. The participants' motor proficiency and skills were assessed when children from the rhythm and the robot groups were engaged in whole-body movement games, whereas the comparison group was playing a tabletop activities. Overall, children from the rhythm and the robot groups improved such skills like gross motor performance, imitation/praxis and interpersonal synchrony. In comparison, children from the control group did not show significant improvement in gross motor performance.

One of the most useful guides in developing game scenarios for robot-assisted play for children with ASD is suggested by IROMEC team in Robins et al. [15]. They proposed three game scenarios tailored for the needs of autistic children. The games are mostly collaborative developed through a series of field studies. The resulting scenarios include suggestions on robot configuration, game instructions and objectives. The scenarios were deployed in a 3-month study with either a group or an individual 40- minute sessions per week with 4 children aged 6-11 years old who had different cognitive and physical disabilities. As a result, children showed significant improvement in skills related to their disability. For example, a child with ADHD improved the skills such as maintaining attention and respecting the rules of game-play.

As Huijnen et al. [16] reported that robot developers tend to target specific skills (e.g. imitation, turn-taking, perspective taking) rather than exploring other ASD objectives such as children's emotional well-being. In contrast to related work, we co-created robotic behaviors by involving therapists and other stakeholders into the design process that were then accordingly evaluated via several iterations. Due to such patient-centered approach, the proposed methodology of robot-assisted play aims to improve children's imitation and turn-taking skills while maintaining an emotional well-being. In addition, with the utility of a commercially-available socially interactive robots (such as humanoid NAO robots), ensuring practical integration into real-world settings that are meaningful and appropriate for various forms of autism is the priority for this work.

\section{Method}

Any interaction design (ID) involves activities such as identifying needs, establishing requirements, developing a number of prototypes that meet those requirements, and evaluating these prototypes by users and other stakeholders. And this process is almost always iterative, which means that it might take a few of these cycles. Due to such iterative ID approach of the RAP methodology, we were able to improve it from cycle to cycle based on our experience and recommendations from other stakeholders (doctors and hospital management). In addition, due to such user-centered design approach, we evaluated prototypes of robot behaviors via observations of child-robot interactions and semi-structured interviews with therapists and parents.

\subsection{Understanding users}

The first step was to understand the needs of children with diverse form of ASD that is often is co-occurred with ADHD as we needed to take into account cognitive processes involved and cognitive limitations of the users.

We envision to involve the following cognitive processes into the RAP: attention, perception and recognition, memory, speaking and listening, decision-making, 


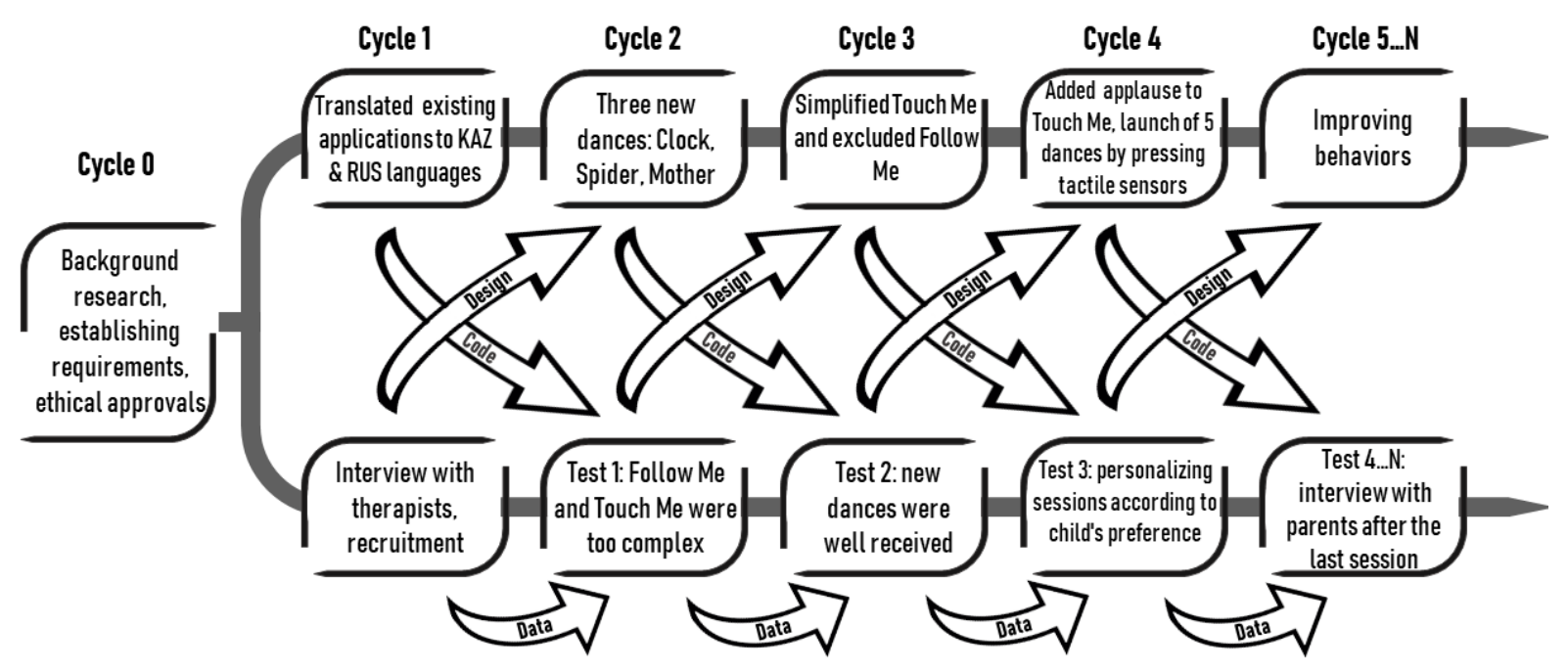

Figure 1: Iterative design flow of the proposed RAP methodology.

and learning. The primary goal for the RAP is to capture and maintain children's attention, thus each application needs to:

- utilize robot's LEDs in its eyes to focus or divert user's attention,

- utilize robot's built-in functionality of head movement in response to face and/or sound tracking,

- use pointing gestures with arm and head movement,

- use of additional material such as printed pictures, musical instruments and others,

- avoid complex wording, compound sentences, aim for simple and crisp phrases,

- avoid the use of too many modalities,

- use familiar movements and sounds,

- facilitate learning of how to interact with a robot via experience e.g. be user-friendly and predictable.

These design principles were discussed with the therapists, who approved using them in the implementation of our RAP applications. They also suggested to implement a game with a ball but we decided to exclude it due to technical limitations of the robot. The goal for the RAP applications used in our methodology is to provide autonomy by avoiding Wizard-of-Oz techniques to simulate perceptual or other robot's limitations. Thus, we only focused on developing applications that are completely autonomous in order to avoid the need for a technical person. Future research and deployment of RAP on a large scale could then be performed without the need for engineers and developers to operate the robot. Thus, we utilized tactile sensors as much as possible. The complete autonomy for a 15min interaction was not desired though due to the need of customizing each individual session according to the observed preferences. Further details on hardware and software components are described in Section 3.3.

\subsection{Requirements for the setup}

In terms of the environment for the robot-assisted therapy, our requirements were met by establishing collaboration with Children's Rehabilitation Center, where children and their parents are hospitalized for a 21-day period to undergo therapy. On the first day of their stay, children undergo diagnostic checks by the doctors while therapists learn about each child's individual differences.

From the hospital management we asked for the small room for our research that had minimal furniture and distractions in it. For the first RAP cycle, we were provided with a small room that had a sofa and a table with a desktop computer, which is usually used by the doctors as an exam room of newcomers. It was made available for us during our first RAP ID life cycle.

And for the second RAP ID life cycle, we were provided with a room that was usually used as a sensory room two times a week only (Mondays and Fridays). We then asked if we could use this room during the remaining week days and it was the ideal room for the RAP. Figure 2 demonstrates our final setup: a child, a robot and one the researchers sit on the floor or sport mats. 


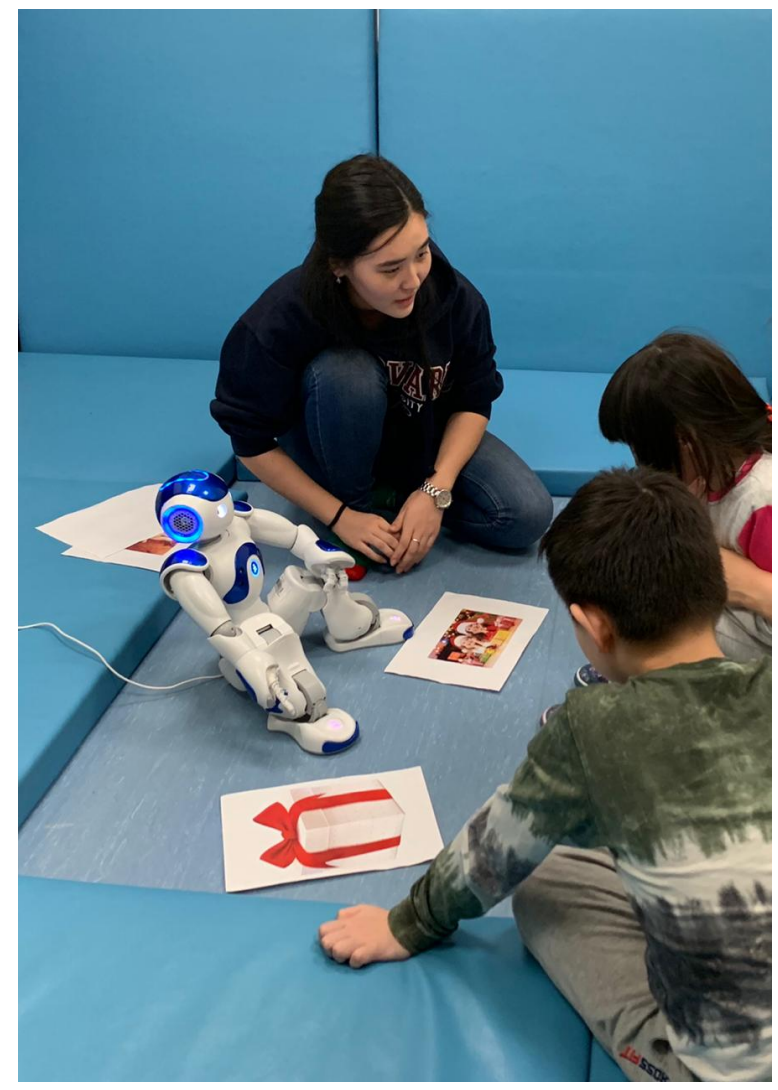

Figure 2: Experimental setup during second interaction design phase.

\subsection{Hardware and software components}

After careful thinking, we decided to have minimal equipment for quick and fast deployment on every day basis: a webcam connected to a laptop, a router for the local Wi-Fi network, two NAO robots, and two laptops to control the robot and to record the interactions. All this equipment was portable in a standard suitcase. We realized through experience that it is important to have a second NAO robot to be always available in a sleeping mode for unforeseen technical issues. These issues would usually happen after two-three hours of constant use of the NAO robot.

For the functional requirements of the robot-assisted therapy, we consulted with doctors and therapists about their requirements for their routine therapies tailored for such children. One of the music therapists suggested to make use of the same songs and sounds that are used in her lessons to learn about musical instruments. Physiotherapist suggested to include physical exercises such as bending, stretching and others to be repeated after the robot. Another therapist suggested implementing her lesson on learning about emotions using photos of real humans. There were also suggestions to include learning games on the topic of animals, various kinds of transport and pretend play furniture.

\subsection{Ethical challenges}

We solicited ethical approvals from the university's and hospital's separate ethical committees. All research members were required to complete Collaborative Institutional Training Institute (CITI) web-based training program on Social/Behavioral Research.

The review committee raised the following issues that we addressed in the following way:

- To describe the risks: As suggested by Riek and Howard [17], our response was: "There is a potential risk that participants might develop strong psychological and emotionally important bonds with the robot, the severing of which at the end of a project can have harmful effects on the subject, perhaps negating any therapeutic benefit the subject might have experienced or even leaving the subject in worse condition than before the research began."

- To minimize risks without compromising research objectives - "Verbal content of the robot will not include words such as "friend", "love", "miss", and other words that might cause emotional connection."

- To minimize the potential consequences to the subjects if the risks become realized - "While it is not anticipated, there is a chance that risks become realized. Parents will be advised by the Informed consent and reminded every session that they are free to decline to participate in any session or ask to cease their participation in the whole project. Parents will also have an opportunity to view and suggest amendments to robot behaviors and transcripts. Parents will be reminded of their right to withdraw unprocessed re-identifiable and individually identifiable data at any point during the project."

\subsection{Recruitment}

Since all families arrive to the Rehabilitation Center on the same day, we waited until families adjusted to the system at the hospital. After a few days, we asked the therapists and nurses to invite all parents with children to the common area of the hospital, so that children and parents can see the robot.

During this demonstration, the robot did not produce any sound but it was turned on in the alive mode. One of the researchers explained the purpose of the research, 
data collection mechanisms, risks and benefits, the procedures and other useful information. The consent forms were distributed and parents had an opportunity to ask questions. All researchers were available to answer any specific questions from each parent. Parents were given opportunity to take a written consent form with them to read at their own pace, and they were given a phone number to call for any clarifications. We stayed around the common area for about two hours for further questions. Most parents signed consent forms within the two hours, but there were parents that returned a signed consent form the next day.

We asked for parents' phone numbers and their permission to be included in a group chat for scheduling purposes and communications of any changes in the timetable. It should be noted that all parents willingly agreed to join the group as they already knew each other before the study and were in friendly relationships due sharing the same common areas, eating meals five times a day together and so on.

\subsection{Structure of the study}

All participants met with the robot up to six times. Each session was approximately fifteen minutes, but it would stop earlier if a child showed disinterest or left the room. The reason for varying number of sessions for each participant was due to personal reasons (e.g. child was asleep or in the swimming pool). We had a number of robot behaviors that we added slowly depending on the child's individual performance and engagement with the robot. For example, on the first session the robot danced two songs, told a short fairy tale, and played "Touch Me" game. For the second session, we added an additional dance and an additional story. Throughout all sessions, it was decided to introduce new applications in each session to be able to understand the preferences and individual needs.

Thus, for the third and latter sessions, the order of applications and the type of applications were adapted to suit individual's engagement level and demonstrated preference. Some children disliked dances and music, others liked only dances and music, but did not like touching the robot. Following the same interaction flow for every child was not possible due to diverse forms of ASD and ADHD. We based our customization of the order and type of applications on our observations, therapist's and parent's feedback.

\subsection{Measurements}

Observations of the sessions were recorded using notes and a small web camera placed slightly behind the robot. We also interviewed parents two times: after the first session and after the last session. Semi-structured interviews were audio recorded upon the permission of the parents. Questions are presented in Sections 4.4 and 5.4.

\section{ID phase 1}

This section reports the first iteration of the proposed RAP methodology utilised in the hospital settings. Each child interacted with the robot on several occasions every other day for approximately 15 minutes. We implemented different applications on the robot that were fine-tuned from session to session. Each session was administered by the therapist. In addition to observational data, we conducted interviews with children's parents. Figure 1 demonstrates iterative evaluations of the robot behaviors and the implemented changes.

\subsection{Participants}

We recruited six participants ( 5 males, 1 female) aged 38 years old with diverse form of ASD and ADHD. Table 1 provides a summary of children's characteristics. Brief descriptions about the participants were provided to us by the doctors and therapists, some other specific information (favourite toys, colors, use of smartphones, etc.) was solicited from parents. All children were nonverbal. But P6 used short phrases but without a communicative orientation. There were mainly learned phrases from advertisements or TV shows. Five children had both ASD and ADHD. Many of them had aggression and anxiety.

\subsection{Behaviors}

This section reports the resulted robot's behaviors from our iterative interaction design process (Figure 1) and how children with varying forms of ASD and ADHD interacted with these behaviors.

All the robot applications were implemented using the "Choregraphe" software developed by Aldebaran Robotics for their robots. One of the games was downloaded from the Aldebaran Store, two were downloaded from the GitHub and remaining games were developed by us. Video 
Table 1: Children's Characteristics.

\begin{tabular}{|c|c|c|c|c|c|c|c|c|}
\hline Child & Age & Sex & Verbal & ADHD & Stereotyped behaviors & Compliance & Favourites & Other Notes \\
\hline$\overline{P 1}$ & 6 & $M$ & No & Yes & Aggression & Yes & Staffed animals & $\begin{array}{l}\text { Interest in others through ob- } \\
\text { servation, eye-contact, mo- } \\
\text { tor imitation }\end{array}$ \\
\hline$\overline{\mathrm{P} 2}$ & 8 & $M$ & No & Yes & $\begin{array}{l}\text { Hand flapping, jumping, or } \\
\text { screaming. Anxiety }\end{array}$ & Yes & No & $\begin{array}{l}\text { Strong attachment to father, } \\
\text { tactile contact }\end{array}$ \\
\hline$\overline{P 3}$ & 7 & $M$ & No & No & Sensory search & Yes & No & $\begin{array}{l}\text { No interest in others, no eye } \\
\text { contact, no gaming skills }\end{array}$ \\
\hline$\overline{\mathrm{P} 4}$ & 6 & M & No & Yes & Self-aggression, anxiety & No & No & $\begin{array}{l}\text { Loves music, no gaming } \\
\text { skills }\end{array}$ \\
\hline$\overline{\mathrm{P} 5}$ & 8 & $\mathrm{~F}$ & No & Yes & $\begin{array}{l}\text { Running, hand flapping, } \\
\text { shacking, high anxiety }\end{array}$ & No & No & $\begin{array}{l}\text { No interest in others, fleeting } \\
\text { eye contact, can laugh/cry } \\
\text { for no reason }\end{array}$ \\
\hline$\overline{\mathrm{P} 6}$ & 5 & $M$ & No & Yes & No & No & No & $\begin{array}{l}\text { Loves music, likes sound } \\
\text { making toys, avoids contact } \\
\text { with others, weak eye con- } \\
\text { tact, short phrases learned } \\
\text { from TV }\end{array}$ \\
\hline$\overline{\mathrm{P} 7}$ & 7 & $M$ & Yes & No & Finger sucking & Yes & No & $\begin{array}{l}\text { Interested in others, emo- } \\
\text { tional, attentive }\end{array}$ \\
\hline$\overline{P 8}$ & 4 & $M$ & Yes & No & $\begin{array}{l}\text { Screaming, shouting or ask- } \\
\text { ing questions }\end{array}$ & No & No & $\begin{array}{l}\text { Weak eye contact, poor com- } \\
\text { munication skills, simple } \\
\text { sentences }\end{array}$ \\
\hline$\overline{P 9}$ & 5 & $\mathrm{~F}$ & No & Yes & $\begin{array}{l}\text { Bubbles with slobber, run- } \\
\text { ning, jumping, attached to } \\
\text { numbers }\end{array}$ & Yes & No & $\begin{array}{l}\text { Likes music, interest in musi- } \\
\text { cal toys, likes a ball pool }\end{array}$ \\
\hline$\overline{\mathrm{P} 10}$ & 5 & $M$ & No & No & $\begin{array}{l}\text { Through hands, uses vocal- } \\
\text { ization }\end{array}$ & No & No & Weak eye contact \\
\hline$\overline{\mathrm{P} 11}$ & 4 & $M$ & No & No & Aggression & Yes & No & $\begin{array}{l}\text { Quick loss of interest, pas- } \\
\text { sive and gets tired fast }\end{array}$ \\
\hline$\overline{\mathrm{P} 12}$ & 3 & $M$ & No & No & No & Yes & No & $\begin{array}{l}\text { No interest in others, tactile } \\
\text { touching }\end{array}$ \\
\hline$\overline{\mathrm{P} 13}$ & 3 & $M$ & No & No & $\begin{array}{l}\text { Putting the toys along the } \\
\text { vertical or horizontal row }\end{array}$ & Yes & No & Interested in others \\
\hline$\overline{\mathrm{P} 14}$ & 3 & $M$ & No & No & $\begin{array}{l}\text { Putting the toys along one } \\
\text { row }\end{array}$ & Yes & Horse & $\begin{array}{l}\text { Interested in toys, eye } \\
\text {-contact, motor imitation }\end{array}$ \\
\hline
\end{tabular}

demonstrations of robot applications can be found at the link: shorturl.at/bdfil.

\subsection{1 “Follow Me" game}

This game was introduced to children first with a story behind the robot. It was explained that the robot was made recently and it needed to learn things slowly and practice a lot. It was explained that walking was the first thing the robot learned. Child's mission was to hold NAO's hand to keep the robot from falling so that the robot could practice its new skill. Due to the fact that the robot itself was already an exciting factor, we took advantage of the robot's size, appearance and its slow walking behavior to gradually introduce the robot to children. Since NAO is very slow, it required children to walk slowly despite their excessively hyperactive nature. This activity was downloaded from the Aldebaran Store. The robot asks to take its hand, rises its hand and waits for someone to hold and pull it in the direction of the walk. The robot stops when the hand is released.

Two participants (P1, P2) had negative experience with the game, since they had troubles with grasping the robot's hand and pulling it slowly. Participants lost their patience and became aggressive. Also, this negative first experience with the robot may be the reason of further aggression of $\mathrm{P} 2$ towards the robot. Other participants also encountered the problem of robot's hand slipping from their hand during the walk, since they couldn't understand how to hold it properly. Some of them tried to pull 
robot's fragile fingers, others tried to hold its wrist. During one of the sessions, one child broke the robot's finger.

Due to these negative reactions, it was decided not to include this behavior in further sessions.

\subsection{2 "Touch Me" game}

This game is intended to develop skills of tactile contact through the interaction with the robot. Another aim was to learn the names of various body parts. NAO kindly asks to touch a particular body part. If a child touches the named tactile sensor, the robot congratulates the child and applauds. For the first session, the robot would count the number of correctly pressed parts. We realized that most children did not follow therapist's or robot's instructions. The body parts were pressed by either a researcher, a therapist or a parent. For these reasons, we had to change this functionality after seeing that children are not compliant and that counting number of correctly pressed sensors is too advanced for the severe ASD children.

We changed the behavior to be without logic and negative feedback and if a child touches the wrong body part, the robot will remain quiet until the correct sensor is touched. In addition, the difference was only between pressing its head, arms and feet. Right and left body parts were counted as the correct answers. To exit the game its head and hand tactile sensors had to be pressed simultaneously. We also changed the wording of the default game: apart from the verb "touch" we used additional verbs to express the same request: "scratch my head", "brush my head", "tap my blue toes on my right foot", "stroke a blue spot on my right hand", and others.

Most importantly, we added applause motion (clapping hands) and its corresponding sound in response to the pressed sensor. Three participants (P1, P3, P4) were fond of this application. They seemed enjoying that the robot was complementing and praising their compliance. At the first two sessions, most of them were helped on what to do, but started pressing the robot's parts themselves in the following sessions.

\subsection{3 "Dance with me"}

The main goal of this application is to listen to songs, dance and repeat movements of the robot. At first, we had only three dances: "Tai chi Chuan", "Ganghnam style" and "Macarena". After the first session with all six children, we realized that children respond positively to dances, but were unfamiliar with these songs. As suggested by the therapist, familiar music songs were necessary to be included. She provided us with music files that are used during music therapy sessions. She helped to design robot moves and then we implemented three dances using Choregraphe software. These new dances were implemented: "Clock" from the local cartoon, "Spider" song, and "Mothers". They varied in terms of tempo and pace in order to diversify the range of the movements and music.

After a few sessions, we decided to combine five dances (apart from "Tai chi Chuan" due to its complicated robot movements) to be started by pressing one of the sensors (head, left, right hands, left and right bumpers). This was an effective way to combine tactile interaction with dances for those children that did not like touching the robot. But they quickly learned which part to press to turn on their favourite dance. All participants but P1 seemed to pay attention during the robot dances. Three participants repeated the moves after the robot. P5 liked only this robot's behavior and was disinterested in other behaviors. P5 did not repeat after the robot and only observed closely. She liked when the robot accidentally touched her face when moved its arms, so she would bring her face very closely to the robot.

\subsection{Observations}

P1: From the view of the therapists, starting from the first test day, $P 1$ showed an emotional reaction when played with the robot. He touched the head of the robot with care. Furthermore, starting from the second session, he interacted with the robot with less help from the therapists, which means he became familiar with the robot. In addition, he behaved very well on the second day. As the therapists noticed, if he would play with a human, he would not display such emotional reactions. Besides, it was also observed that the child liked pressing the chest button to get the robot's default response about its IP address. But when we did not let him press the chest button, he became aggressive.

P2: Less noticeable dynamics in behaviour were noted for $P 2$. He was more interested in looking at the robot's dance than interacting and following the robot's instructions. The therapists highlighted aggressive behaviour of the participant towards the robot as he tried pushing it in order to make it fall. This could be explained by the robot's malfunctioning when it was pushed for the first time. It took a few minutes to start another application. Another explanation could be that he liked everyone's reaction when the robot fell, so he wanted to make it happen again. 
P3: According to the therapists $P 3$ demonstrated good progress. As his father said, the child does not like to play with toys. For example, at the first meeting, when the robot got up and gave tasks, he did not comply with the instructions. However, on another day, he remembered all body parts to press and repeated all dance movements. The therapists concluded that it was interesting for the child because it took time for him to accept the robot. At the beginning, he did not want to interact with it, and was crying in his room and showed disinterest.

P4: At the first visit, according to the therapists, P4's behavior was satisfactory: he danced and repeated moves a few times. However, he started playing the game "Touch $M e "$ only after the second session.

P5: As for the P5, the therapists noted significant differences from session to session in the increased interest in interaction with the robot. They also noted significant improvement in establishing eye contact not only with the robot, but with her mother and other people too. This can be counted as a significant success, as the participant does not have any interest in toys, whereas the robot maintained her attention for the duration of all sessions. The therapists also noted improvement in the expression of emotions and tactile interactions. The participant was extremely attentive during the sessions. She was trying to touch the robot, to look into its eyes, and track its motions. Another significant result is that the participant's stereotyped movements were not exhibited during the sessions with the robot. She was highly focused and that showed an improvement in her ability to maintain concentration and pay attention for an extended period of time.

P6: P6 was afraid of the robot on the first day. However, after the second test day he touched the robot. He was emotional about the robot, tracking its motion and laughing at it, especially liked to touch the robot. Moreover, his interest evolved from session to session as he was exploring the robot. The most important observation is that the child did not want to leave on the third day and even said "I am here" meaning that he wants to stay and play with the robot. This was a very unusual behaviour for him because his speech is limited and without communicative meaning. His comprehension of tasks improved from being needing the assistance of the therapists to completing them independently. In addition, the subject started to copy the robot's movements in his daily life.

\subsection{Parents' interviews}

We also interviewed parents of our participants after the last session to get a better understanding of the impact of the interaction with robot on children in their daily life. Questions concerning personal preferences of children were omitted, only the most relevant questions are listed below:

- What do you think about RAP as a therapy for your child? All parents considered RAP helpful and interesting for children.

- What could you compare your child's reaction to a robot with? Was the reaction similar to a toy or, perhaps, seeing an animal? All but one (P3) parents came to the conclusion that the reaction of the child to the robot can not be comparable to the toy. Most of the parents report that the robot caught their attention, which is unusual, since their children are not interested in toys (P1, P2, P6). Two parents reported that their children perceived the robot as a friend.

- Have you noticed any changes in your child's behaviour after each session? Overall? The answers for this question varied, but overall feedback was positive. Parents noticed little details which were unusual for their children but noteworthy in the light of their diagnosis. Here are some of the parents' reports: "he started to speak a little bit", "significant improvement in the eye contact of the child", "child complied to robot's requests", "child started to dance all day long and copy the robotic movement while dancing which is unusual for him, since he did not like dancing during the dance therapy classes before”.

- Could you describe your child's social abilities? Is he/she capable of distinguishing emotions? To what extent does your child maintain an eye contact, a tactile contact? Most of the parents affirmed that their children have difficulties with expressing their desires verbally. All parents noticed increased eye contact with the robot. Also, two parents reported increased eye contact with people after the interaction. One parent said that her child does not like tactile contact with other humans, but was not bothered by the tactile contact with the robot.

- To what extent does your child use technological gadgets such as tablets, phones, and computer? Most of the parents stated that their child frequently utilized this kind of devices. Especially, they liked to watch videos and cartoons. The mother of P5 noticed that her daughter started to show the interest in smartphones during the time spent in the centre.

- Do you have any recommendations for the improvement of the robot behaviors? Any ideas for potential applications? For this question we gathered different answers, but overall, all of them recommended to increase the number of games, to diversify them. Also, one parent insisted on adding songs in Kazakh language. Another 
parent wished the robots would teach the alphabet or the names of domestic items.

\section{ID phase 2}

This section reports our second iteration of the methodology that was conducted in a few months. This time we made the following changes: 1 ) it was in a different room with a robot and a child positioned on the floor, 2) group recruitment of the participants in contrast to approaching them individually, 3) a set of newly developed applications that needed to be evaluated and fine-tuned.

\subsection{Participants}

For the second RAP life cycle, we recruited eight participants (7 male, 1 female) aged 3-8 years old with diverse form of ASD and ADHD. Table 1 provides a summary of children's characteristics. Brief descriptions about the participants were provided to us by the doctors and therapists, some other specific information (favourite toys, colors, use of smartphones, etc.) was solicited from parents. Six children were nonverbal (apart P7 and P8). One child had both ASD and ADHD. Many of them had aggression and anxiety.

\subsection{Behaviors}

Table 2 provides a list of all robot behaviors used for each child in each session. We also report the total time duration for each session and mean for each child. Group mean is 11 minutes.

\subsection{1 "Dance with me"}

Previous cycle had songs only in English and Russian languages. Due to the increased demand of Kazakh songs, we added two more songs in Kazakh: "Kaida" and "Mothers". P9 learned the words of the "Spider" song and would say/sign some words along with the robot, which she never did before according to her mother. That was a very good progress. P7 danced with the robot from the first session onward. Others only observed but did not start dancing themselves. P8 was the only child that did not like this application as he is extremely sensitive to sounds.

\subsection{2 “Emotions"}

This application targets joint attention by exercising child's ability to pay joint attention at the pictures placed on the left side and on the right side of the robot. In addition, the purpose of this application was also to learn and encourage the child to imitate emotions (such as happy, bored, sad, surprised, interested) that were displayed by the robot (with a sound) and children on the pictures. Each emotional state was accompanied with a photograph of a familiar situation so that the child could refer to his or her emotional state in a similar situation.

Each emotion had three phrases accompanied by the robot's movements such as:

- When I get presents like the one on the picture (looks at the picture of the present), I feel happy (demonstrates happiness).

- When I get presents like the one on the picture (looks and points at the picture of the present), I feel happy (demonstrates happiness).

- This child feels happy (looks and points at the picture of a child) when he gets a present (looks and points at the picture of the present). Could you repeat after me?

All emotions had the same stages but with different pictures and different situations such as a broken toy for the sad emotion, waiting for the bus - bored, a full rainbow surprised, a new book - interested, barking dog - fear, and others. It should be noted that we gradually introduced emotions from session to session (two emotions in each session).

This game was interesting to most participants. But only P7 and P8 repeated the emotions after the robot. P14 did not show the emotions but was empathetic when the robot was sad.

\subsubsection{Storytelling}

We animated two folk fairy tales "The Bun" and "The turnip" in two languages. Each story lasted around 3-4 minutes. Children's task was to listen to the stories while the robot demonstrated the animations.

This is the only application that was enjoyed by all children without extreme reactions like aggression or screaming. 


\subsection{4 "Transport"}

We implemented a transport game as suggested by one of the parents. We included four different types of transports: a car, a motorcycle, an airplane, and a boat. Each transport had an animation and a sound. For example, a car animation had NAO imitating holding a steering wheel. During an airplane animation, the robot extended its arms to the sides. As the robot demonstrated one of the transports, it encouraged children to repeat the sound and the motion. The next demonstration was launched by pressing a tactile sensor on one of robot's arms or legs. The child was encouraged to repeat the demonstration, and each animation was repeated in a random order. The goal of this application was to improve children's ability to imitate.

Three participants played this game with the robot (P7, P8, P14). It was similarly enjoyed by the same people as the Emotions game.

\subsection{5 "Animals"}

This game is similar to "Transports" behaviour, but instead of transports, the robot demonstrated four animations of animals: a gorilla, a mouse, an elephant, and a horse with sounds. The robot asked children to guess what the animal is and to repeat the animation.

P14 likes animals and was very excited to see a horse animation as it is his favorite animal. He asked for this animation and we repeated it several times for him. P7 and P8 behaved similarly to "Transport" behavior.

\subsection{Observations}

P7: In the first session P7 was initially scared but quickly adjusted and actively participated in the session. He repeated dances and touched the robot. The session lasted longer than the average therapy time. On the following day, he greeted the robot and remembered its name. He reacted with sensitivity to all emotions demonstrated by the robot, and especially was impressed by the sad emotion and showed sympathy by patting the robot's head. Starting from the third session, the child enthusiastically repeated all dances and recalled emotions learnt the day before. At the end of the session, he gave the high five to the robot. Later, he matched all emotions with pictures of situations correctly and actively participated in all new games. He also was empathetic with the robot when the robot had fallen.
P8: At the first visit I did not like dances but was engaged in the "Touch Me" game. He put a lot of stickers on the robot while smiling and laughing. From the second day, he actively played "Touch Me," correctly recognizing all body parts. He recognized all emotions when the "Emotions" game was introduced but did not repeat them. He showed an unusual reaction to the sadness emotion by blowing on the robot. He demonstrated a negative reaction by screaming on the second attempt to start the dances but quickly calmed down when the robot started to tell a fairy tale. He listened attentively and laughed. The child remained patient when there was a delay due to a technical issue. In the following days, he started to match pictures with emotions, correctly grabbing them by himself and even helped to collect papers from the floor.

P9: According to the therapists, $P 9$ showed the biggest progress during the sessions and her interest evolved. At first, she kept distance and was only interested in observing the robot dancing rather than interacting with it. From the second day, she started to repeat dances and spent more time in the experimental room even after her session. She smiled at the robot on the third day and called it by name. In addition, she said words in response to the robot's questions. For example, in response to: "Do you want to play again?" she said "Yes” and "Again”. She did not want to play games such as "Emotions" and "Touch Me," but she liked the fairy tale "Turnip" and even repeated some words.

P10: Almost no positive dynamics for $P 10$ were noted. He kept close to his mother. He did not repeat any dances and demonstrated an aggressive behavior toward the robot. During the third session, he watched the robot dance for 2 minutes but then again became distracted. In the last sessions, he did not interact with the robot at all, sometimes making aggressive actions, such as hitting the robot's head.

P11: $P 11$ also did not demonstrate a significant progress and missed the half of the sessions. He did not interact with the robot on the first day. In other sessions he played the "Touch Me" game only with the mother's help. During the last session he was calm and listened the story but without paying much attention to other games.

P12: At the first visit, P12's behavior was active. He danced with the robot and walked with it. He played "Touch Me" with the prompt of the mother. On the second session, he touched the robot's eyes. In the following sessions, he did not pay much attention to the robot's actions and only did so with the parent's prompt. However, he smiled when the robot danced and appeared to like touching the robot. 
Table 2 Applications used for each child in each section during ID Phase 2.

\begin{tabular}{|c|c|c|c|c|c|c|c|}
\hline Child & Session 1 & Session 2 & Session 3 & Session 4 & Session 5 & Session 6 & Mean \\
\hline$\overline{\mathrm{P} 7}$ & $\begin{array}{l}\text { Time: } 13.4 \mathrm{~min} \\
\text { (803.4 sec) } \\
\text { Applications: } \\
\text {-Macarena } \\
\text { - Follow Me } \\
\text {-Touch Me }\end{array}$ & $\begin{array}{l}\text { Time: } 9.82 \text { min } \\
\text { (589.2 sec) } \\
\text { Applications: } \\
\text {-Macarena } \\
\text { - Ganghnam } \\
\text { style } \\
\text {-Touch Me } \\
\text {-Emotions } \\
\text {-Tai Chi Chuan }\end{array}$ & $\begin{array}{l}\text { Time: } 11.7 \mathrm{~min} \\
\text { (703.6 sec) } \\
\text { Applications: } \\
\text {-Macarena } \\
\text {-Kaida } \\
\text {-Clock } \\
\text {-Ganghnam } \\
\text { style } \\
\text {-Touch Me } \\
\text {-Emotions }\end{array}$ & $\begin{array}{l}\text { Time: } 12.7 \mathrm{~min} \\
\text { (761.6 sec) } \\
\text { Applications: } \\
\text {-Ganghnam } \\
\text { style } \\
\text {-Clock } \\
\text { - Kaida } \\
\text {-Animals } \\
\text { - Touch Me } \\
\text {-Emotions } \\
\text {-Transport }\end{array}$ & $\begin{array}{l}\text { Time: } 15.2 \text { min } \\
\text { (911 sec) } \\
\text { Applications: } \\
\text {-Clock } \\
\text {-Kaida } \\
\text {-Transport } \\
\text {-Macarena } \\
\text { - Touch Me } \\
\text { - The Turnip } \\
\text {-Animals } \\
\text {-Emotions }\end{array}$ & $\begin{array}{l}\text { Time: } 7.54 \mathrm{~min} \\
\text { (452.4 sec) } \\
\text { Applications: } \\
\text {-Mothers } \\
\text {-Clock } \\
\text { - Spider } \\
\text {-Animals } \\
\text { - Transport }\end{array}$ & $\begin{array}{l}11.7 \\
\min \end{array}$ \\
\hline P8 & $\begin{array}{l}\text { Time: } 18.1 \mathrm{~min} \\
\text { (1084.5 sec) } \\
\text { Applications: } \\
\text {-Touch Me } \\
\text {-Mother } \\
\text {-The Turnip } \\
\text {-Emotions }\end{array}$ & $\begin{array}{l}\text { Time: } 6.03 \text { min } \\
\text { (362 sec) } \\
\text { Applications: } \\
\text {-Touch Me } \\
\text {-The Turnip } \\
\text {-Emotions }\end{array}$ & $\begin{array}{l}\text { Time: } 13.4 \mathrm{~min} \\
\text { (801 sec) } \\
\text { Applications: } \\
\text {-Ganghnam } \\
\text { style } \\
\text { - Clock } \\
\text { - Spider } \\
\text { - The Turnip } \\
\text { - Touch Me } \\
\text {-Emotions }\end{array}$ & $\begin{array}{l}\text { Time: } 15.7 \mathrm{~min} \\
\text { (943 sec) } \\
\text { Applications: } \\
\text {-Animals } \\
\text {-Touch Me } \\
\text {-Emotions } \\
\text {-The Turnip } \\
\text { - Follow Me } \\
\text {-Transport }\end{array}$ & & & $\begin{array}{l}13.3 \\
\min \end{array}$ \\
\hline P9 & $\begin{array}{l}\text { Time: } 7.39 \text { min } \\
\text { (443.37 sec) } \\
\text { Applications: } \\
\text {-Macarena } \\
\text {-Kaida } \\
\text {-Touch Me }\end{array}$ & $\begin{array}{l}\text { Time: } 9.03 \text { min } \\
\text { (542.02 sec) } \\
\text { Applications: } \\
\text {-Macarena } \\
\text {-Ganghnam } \\
\text { style } \\
\text {-Kaida } \\
\text { - Touch Me }\end{array}$ & $\begin{array}{l}\text { Time: } 7 \text { min } \\
\text { (419.9 sec) } \\
\text { Applications: } \\
\text {-Ganghnam } \\
\text { style } \\
\text { - Macarena } \\
\text { - Clock } \\
\text { - Spider } \\
\text {-Kaida }\end{array}$ & $\begin{array}{l}\text { Time: } 16.6 \text { min } \\
\text { (994.02 sec) } \\
\text { Applications: } \\
\text {-Macarena } \\
\text {-Ganghnam } \\
\text { style } \\
\text {-Touch Me } \\
\text {-Kaida }\end{array}$ & $\begin{array}{l}\text { Time: } 12.7 \text { min } \\
\text { (762.27 sec) } \\
\text { Applications: } \\
\text {-Ganghnam } \\
\text { style } \\
\text {-Spider } \\
\text {-Clock } \\
\text {-Macarena }\end{array}$ & $\begin{array}{l}\text { Time: } 11.2 \text { min } \\
\text { (674.83 sec) } \\
\text { Applications: } \\
\text {-Mothers } \\
\text { - Clock } \\
\text { - Spider } \\
\text {-Macarena } \\
\text { - Ganghnam } \\
\text { style } \\
\text {-The Turnip } \\
\text {-Kaida }\end{array}$ & $\begin{array}{l}10.6 \\
\min \end{array}$ \\
\hline $\mathrm{P} 10$ & $\begin{array}{l}\text { Time: } 8.82 \text { min } \\
\text { (528 sec) } \\
\text { Applications: } \\
\text {-Macarena } \\
\text {-Ganghnam } \\
\text { style } \\
\text { - Touch Me } \\
\text { - other dance }\end{array}$ & $\begin{array}{l}\text { Time: } 8.21 \mathrm{~min} \\
\text { (492.8 sec) } \\
\text { Applications: } \\
\text { •Macarena } \\
\text {-Ganghnam } \\
\text { style } \\
\text {-Touch Me }\end{array}$ & & $\begin{array}{l}\text { Time: } 20 \text { min } \\
\text { (1231.19 sec) } \\
\text { Applications: } \\
\text {-Mothers } \\
\text { - Clock } \\
\text { - Spider } \\
\text {-Animals } \\
\text {-Touch Me } \\
\text {-The Turnip }\end{array}$ & $\begin{array}{l}\text { Time: } 15.5 \text { min } \\
\text { (928.14 sec) } \\
\text { Applications: } \\
\text {-The Turnip } \\
\text { - Ganghnam } \\
\text { style } \\
\text {-Mothers } \\
\text {-Clock } \\
\text {-Spider } \\
\text {-Touch Me } \\
\text {-Emotions }\end{array}$ & & $\begin{array}{l}13.1 \\
\min \end{array}$ \\
\hline $\bar{P} 11$ & $\begin{array}{l}\text { Time: } 5.33 \mathrm{~min} \\
\text { (319.91 sec) } \\
\text { Applications: } \\
\text {-Macarena } \\
\text {-Touch Me } \\
\text {-Ganghnam } \\
\text { style }\end{array}$ & $\begin{array}{l}\text { Time: } 9.24 \text { min } \\
\text { (554.77 sec) } \\
\text { Applications: } \\
\text {-Touch Me } \\
\text {-The Turnip } \\
\text {-Ganghnam } \\
\text { style } \\
\text {-Macarena } \\
\text {-Kaida }\end{array}$ & $\begin{array}{l}\text { Time: } 8.34 \mathrm{~min} \\
\text { (500.44 sec) } \\
\text { Applications: } \\
\text {-Ganghnam } \\
\text { style } \\
\text {-Macarena } \\
\text {-Kaida } \\
\text {-Touch Me }\end{array}$ & $\begin{array}{l}\text { Time: } 8.96 \text { min } \\
\text { (537.45 sec) } \\
\text { Applications: } \\
\text {-The Turnip } \\
\text {-Animals } \\
\text {-Touch Me } \\
\text {-Kaida }\end{array}$ & & & $\begin{array}{l}7.96 \\
\min \end{array}$ \\
\hline
\end{tabular}


Table 2 (continued)

\begin{tabular}{|c|c|c|c|c|c|c|c|}
\hline Child & Session 1 & Session 2 & Session 3 & Session 4 & Session 5 & Session 6 & Mean \\
\hline$\overline{P 12}$ & $\begin{array}{l}\text { Time: } 7.35 \mathrm{~min} \\
\text { (441 sec) } \\
\text { Applications: } \\
\text {-Macarena } \\
\text { - Touch Me } \\
\text { - Follow Me } \\
\text { - Ganghnam } \\
\text { style }\end{array}$ & $\begin{array}{l}\text { Time: } 1.38 \mathrm{~min} \\
(82.8 \mathrm{sec}) \\
\text { Applications: } \\
\text {-Macarena }\end{array}$ & $\begin{array}{l}\text { Time: } 4.84 \text { min } \\
\text { (290.3 sec) } \\
\text { Applications: } \\
\text { - Mothers } \\
\text {-Clock } \\
\text {-Spider } \\
\text {-Touch Me } \\
\text {-Animals } \\
\text {-The Turnip }\end{array}$ & $\begin{array}{l}\text { Time: } 11.7 \mathrm{~min} \\
\text { (699 sec) } \\
\text { Applications: } \\
\text { - Touch Me } \\
\text {-Emotions } \\
\text { - The Turnip } \\
\text {-Animals } \\
\text { - Macarena } \\
\text { - Spider }\end{array}$ & & & $\begin{array}{l}6.32 \\
\min \end{array}$ \\
\hline$\overline{\mathrm{P} 13}$ & $\begin{array}{l}\text { Time: } 6.59 \mathrm{~min} \\
\text { (395.24 sec) } \\
\text { Applications: } \\
\text {-Macarena } \\
\text { - Follow Me } \\
\text { - Ganghnam } \\
\text { style } \\
\text { - Touch Me } \\
\text {-Kaida }\end{array}$ & $\begin{array}{l}\text { Time: } 14.9 \text { min } \\
\text { (892.74 sec) } \\
\text { Applications: } \\
\text {-Macarena } \\
\text { - Ganghnam } \\
\text { style } \\
\text {-Mothers } \\
\text { - Touch Me } \\
\text {-Emotions }\end{array}$ & & & & & $\begin{array}{l}10.75 \\
\min \end{array}$ \\
\hline$\overline{\mathrm{P} 14}$ & $\begin{array}{l}\text { Time: } 11.4 \text { min } \\
\text { (680.94 sec) } \\
\text { Applications: } \\
\text {-Ganghnam } \\
\text { style } \\
\text {-Macarena } \\
\text { - Follow Me }\end{array}$ & $\begin{array}{l}\text { Time: } 15.5 \text { min } \\
\text { (929.18 sec) } \\
\text { Applications: } \\
\text {-Macarena } \\
\text {-Ganghnam } \\
\text { style } \\
\text {-Kaida } \\
\text {-Animals }\end{array}$ & $\begin{array}{l}\text { Time: } 17.8 \mathrm{~min} \\
(1070.62 \mathrm{sec}) \\
\text { Applications: } \\
\text {-Animals } \\
\text { - Touch Me }\end{array}$ & $\begin{array}{l}\text { Time: } 4.99 \text { min } \\
\text { (299.15 sec) } \\
\text { Applications: } \\
\text {-Ganghnam } \\
\text { style } \\
\text {-Clock } \\
\text { - Macarena } \\
\text { - Kaida }\end{array}$ & $\begin{array}{l}\text { Time: } 19.8 \mathrm{~min} \\
\text { (1186.24 sec) } \\
\text { Applications: } \\
\text {-Transport } \\
\text {-Kaida } \\
\text {-Clock } \\
\text {-Animals } \\
\text { - Mothers } \\
\text { - Macarena } \\
\text { - Touch Me }\end{array}$ & $\begin{array}{l}\text { Time: } 15.1 \mathrm{~min} \\
\text { (904.03 sec) } \\
\text { Applications: } \\
\text {-Ganghnam } \\
\text { style } \\
\text {-Kaida } \\
\text { - Macarena } \\
\text {-Touch Me } \\
\text {-Transport } \\
\text {-Animals }\end{array}$ & $\begin{array}{l}14.09 \\
\min \end{array}$ \\
\hline
\end{tabular}

P13: P13 participated only two times and there were no changes or active interactions noted during the two sessions. He did not repeat dances and kept close to his mother. However, he looked at the robot's eyes, even though he has problems with maintaining eye contact with people. This suggests that the therapy could be beneficial for this child if he continued to attend.

P14: To begin with, P14 demonstrated an immediate interest to the robot by trying to show the cell phone to it. On the second day, he recognized the robot and showed an unusual behavior. He left the room to everyone's surprise and brought the consent form with the picture of the robot from his room. He did not repeat dances but seemed to like touching it. The third therapy was interrupted, because the child became distracted with the objects in the room. In the following days, he showed less interest towards the robot by keeping close to his mother, where he danced a little bit. Nevertheless, he seemed to like to investigate the robot as he touched its head, hands and back, and appeared trying to show something to the robot by bringing it very close to its eyes.

\subsection{Parents' interviews}

We also interviewed parents of our participants after the last session to get a better understanding of the impact of the interaction with the robot on children.

- What do you think about RAP as a therapy for your child? All of the interviewees responded that they would like to continue RAP in the future.

- What could you compare your child's reaction to a robot with? Was the reaction similar to a toy or, perhaps, seeing an animal? Three parents compared the way their child got emotional with the interaction with some animal like puppy or horse. Another parent responded that her child expressed such emotions during the drawing.

- Have you noticed any changes in your child's behaviour after each session? Overall? The mother of P9 reported that the robot helped her daughter to stay focused. Also, she and P8's mother noticed that during the interaction their child was sitting calmly, whereas outside they could not even walk with a medium pace. Parents of P7 and P12 noted that after several interactions with the robot their children started to dance with the robot. 
- Could you describe your child's social abilities? Is he/she capable of distinguishing emotions? To what extent does your child maintain an eye contact, a tactile contact? Parents of three subjects reported that they can distinguish emotions. Two of them are not empathetic and one recently started to demonstrate empathy.

- To what extent does your child use technological gadgets such as tablets, phones, and computer? All parents stated that their children are familiar with the gadgets. As in the previous group, subjects tend to watch videos rather than playing games.

- Do you have any recommendations for the improvement of the robot behaviors? Any ideas for potential applications? Parents in this cycle were more specific in their recommendations. P8's and P12's mothers recommended to add more repetitions and commands in games. Regarding "Emotion recognition" game, P9's mother suggested including words for representing emotions because it was hard to understand the feelings of the robot by sounds and movements alone. P14's mother requested more familiar songs and dances, since her child did not recognize the "Macarena" dance.

\section{Discussion}

One of the goals was to design appropriate behaviors for children with severe form of both ASD and ADHD. We wanted to develop appropriate RAP applications to be both entertaining and educational. Throughout this experience, we highlight the following considerations for future research:

- Presence of parents. Initially, after researching related works, we decided that we will have classical triadic interaction between a child, a robot and a therapist. But after consulting with the therapists and getting more familiar with the severe form of autism and their needs and behavioral challenges, it was decided to invite parents to attend the sessions. It proved to be useful for the following reasons: 1) children felt relaxed due their parents' presence, 2) interviewing parents provides useful information on child-robot interaction, 3) robot might facilitate bonding with a parent through sharing this novel experience. While there were some parents who stopped attending the sessions after realising that their children are doing fine by themselves and wanted to take this time to rest (P9), there are some children that needed their parents next to them all the time. It is an interesting research question to understand whether children have to be separated from their parents to facilitate more effective RAP. But it seemed like many children would not stay as long as they did in the room without their parent, thus the whole RAP might be then less effective for them. Again, customization for each individual child's case might be needed to achieve the best results. In addition, apart from observations and other metrics, it is important to talk to children's caregivers as they are sometimes the most qualifying respondents who can spot and report even slight differences in their children's behaviors. However, asking appropriate questions at the right time is difficult, but researchers could consider administering a questionnaire to parents after every session. Our current interviews are not informative as the questions are too general, so future work should address this limitation.

- Portable setup. The initial plan was to make a triadic interaction with the setup similar to the DREAM's intervention table setup [18]. However, we realized that it is unpractical to have a complicated setup that needs to be assembled on daily basis. To this end, it was decided to avoid complex setup and to have one standard camera rather than a set of cameras. With the recent advancements of computer vision solutions, gaze tracking and facial expressions analysis could be extracted from RGB video feed without the need for the depth camera. In addition, many external cameras could easily make children and parents uncomfortable, thus we opted for having only one webcamera that was posited to capture children's front view.

Throughout this experience, the ideal setup included 2 NAO robots, two laptops, Wi-Fi router and printed pictures for the games. The second robot was used as a backup. Since we frequently encountered problems with the robot, we needed to be able to switch from one robot to another as fast as possible. As a consequence, presence of the researchers in the room was unavoidable.

- Presence of researchers. The presence of researchers in the room along with the therapist and parent is justified by the following reasons. First reason, as was mentioned above, is in the case of technical problems with the robot. Another reason is to hold the robot during expressive motions since it can lose its stability and fall which would lead to a delay in the interaction. Delays made children very unhappy and often caused them being aggressive towards the robot.

- Assistance. As reported in Wood et al. [6], providing assistants is quite normal as children might need help from their parents, therapists or researchers. Due to varying abilities, some children might need assistance to learn how to interact with the robot. But it is important to give children a few seconds before helping them, especially 
during latter sessions, for an opportunity to do it by themselves.

- Comparison to other methods. To avoid limitations stated in the related work $[6,7,13]$, the setup of our work aimed for portability, minimum requirements and fast deployment on daily basis. Our setup might be less effective than the Dream Lite [9], which avoided the need to have a robot operator and an assistant (therapist) by the child side at the same time as the robot control is performed through the tablet. However, we believe that a severe form of autism requires these two roles to be split between different people due to a more challenging nature of the therapy. Our experience in the wild settings suggests that the NAO robot is not yet ready to deliver plug and play capability for a non-technical specialist and thus, a collaboration between at least one technical specialist and at least one therapist is needed for a long-term robot-assisted therapy research. A possible disadvantage of the proposed method is due to a time limit of a 21-day period and a very busy schedule of the parents that made it difficult at times to create a timetable that would suit everyone. On the other hand, it is a very convenient environment to recruit large number of participants for an external validity of the studies. Another important advantage is that the same children return to the center to repeat the program every year which could allow us to conduct a long-term experiment. In this work, addressing the needs of a low-functioning autism in combination with ADHD was important due to a relative neglect of robot-assisted therapy efforts to address additional challenges facing individuals with low-functioning autism such as impairments of language and intellectual ability.

\section{Conclusion}

This paper contributes with a set of robot behaviors suitable for the Robot-Assisted Therapy for children with diverse forms of ASD and ADHD that were carefully designed and evaluated via several iterations and by involving therapists, doctors, and parents into the design process. From our observations and parents' interviews we can conclude that RAP had positive outcomes for most children. Some children had noticeable outcomes, such as $\mathrm{P} 5$ who started looking into her mother's eyes after around five sessions. P9 never expressed words with a meaning before, but she said "Again" a few times asking the robot to dance more. She also sang along during "Spider" song. This song and dance was her favourite, so she pressed only that particular body part. There was another participant who said his first word to the robot - "Bye". And, finally, one child, who usually avoids people, gave a high five gesture to all researchers after one of the sessions. All of these and other positive moments motivate us to continue this research. Future work will include utilising the implemented methodology on a new cohort of children and then perform video coding of their behaviors to extract quantitative data for each child.

Contrary to standard HRI practices to follow same interaction flow for each participant, we believe that children with a severe form of ASD need customized RAP session according to their preferences. Since the value provided by robot can only be gained if the child actually spends time interacting with it, our goal is to facilitate interaction to engage and attract children's attention. Thus, the type of robot's behaviors and the order of them should be tailored specifically for different cases to meet needs of a given participant. As suggested by the therapists, diverse needs and preferences of children need to be met with appropriate games and robot behaviors. As suggested by the parents, we will continue to expand the library of developed applications to allow for a more interactive and engaging RAP. This work sets the foundation adhering to rigorous ethical standards and contributes with its methodology of a potential utility of such off-the-shelf humanoid robots for research and practice by rehabilitation centers.

Acknowledgments: We would like to thank all families for their participation and medical staff of Children's Rehabilitation Center for their help and cooperation throughout this research.

\section{References}

[1] K. Richardson, et al., Robot enhanced therapy for children with autism (DREAM): A social model of autism, IEEE Technology and Society Magazine, 2018, 37(1), 30-39

[2] K. Dautenhahn, Robots as social actors: Aurora and the case of autism, In: Proceedings of The Third International Cognitive Technology Conference (1999, San Francisco, USA), San Francisco, 1999, 374

[3] B. Scassellati, H. Admoni, M. Matarić, Robots for use in autism research, Annual review of biomedical engineering, 2012, 14, 275-294

[4] J. Diehl, L. Schmitt, M. Villano, C. Crowell, The clinical use of robots for individuals with autism spectrum disorders: A critical review, Research in autism spectrum disorders, 2012, 6(1), 249-262, DOI:10.1016/j.rasd.2011.05.006

[5] B. Tleubayev, Z. Zhexenova, A. Zhakenova, A. Sandygulova, Robot-assisted therapy for children with ADHD and ASD: a pilot study, In: Proceedings of the 2nd International Conference 
on Service Robotics Technologies (2019, Beijing, China), China, 2019, 58-62, DOI:10.1145/3325693.3325703

[6] L. Wood, B. Robins, G. Lakatos, D. Syrdal, A. Zaraki, K. Dautenhahn, Developing a protocol and experimental setup for using a humanoid robot to assist children with autism to develop visual perspective taking skills, Paladyn, Journal of Behavioral Robotics, 2019, 10(1), 167-179, DOI:10.1515/pjbr-2019-0013

[7] H.-L.Cao, et al., Robot-enhanced therapy: development and validation of supervised autonomous robotic system for Autism Spectrum Disorders Therapy, IEEE Robotics \& Automation Magazine, 2019, 26(2), 49-58, DOI:10.1109/mra.2019.2904121

[8] D. David, C. Costescu, S. Matu, A. Szentagotai, A. Dobrean, Effects of a robot-enhanced intervention for children with ASD on teaching turn-taking skills, Journal of Educational Computing Research, 2019, DOI:10.1177/0735633119830344

[9] A. Mazel, S. Matu, DREAM Lite: Simplifying robot assisted therapy for ASD, In: Proceedings of the second Workshop of Social Robots in Therapy and Care, in conjunction with the 14th ACM/IEEE International Conference on Human-Robot Interaction (2019, Daegu, Korea), Daegu, 2019,

[10] C. Lord, M. Rutter, P. DiLavore, S. Risi, K. Gotham, S. Bishop, Autism diagnostic observation schedule - 2nd edition (ADOS2), Los Angeles, CA: Western Psychological Corporation, 2012

[11] E. S. Kim, et al., Social robots as embedded reinforcers of social behavior in children with autism, Journal of Autism and Developmental Disorders, 2012, 43(5), 1038-1049, DOI:10.1007/s10803-012-1645-2
[12] L. Boccanfuso, J. O'Kane, CHARLIE: An adaptive robot design with hand and face tracking for use in autism therapy, International Journal of Social Robotics, 2011, 3(4), 337-347, DOI:10.1007/s12369-011-0110-2

[13] A. Tapus, et al., Children with autism social engagement in interaction with NAO, an imitative robot: A series of single case experiments, Interaction Studies, 2012, 13(3), 315-347, DOI:10.1075/is.13.3.01tap

[14] S. Srinivasan, K. Maninderjit, I. Park, T. Gifford, K. Marsh, A. $B$ hat, The effects of rhythm and robotic interventions on the imitation/praxis, interpersonal synchrony, and motor performance of children with Autism Spectrum Disorder (ASD): A pilot randomized controlled trial, autism research and treatment, 2015, Article ID 736516, DOI:10.1155/2015/736516

[15] B. Robins, et al., Scenarios of robot-assisted play for children with cognitive and physical disabilities, Interaction Studies, 2012, 13(2), 189-234, DOI:10.1075/is.13.2.03rob

[16] C. Huijnen, M. Lexis, L. de Witte, Matching robot KASPAR to autism spectrum disorder (ASD) therapy and educational goals, International Journal of Social Robotics, 2016, 8(4), 445-455

[17] L. Riek, D. Howard, A code of ethics for the human-robot interaction profession, Proceedings of We Robot, 2014

[18] P. Esteban, et al., How to build a supervised autonomous system for robot-enhanced therapy for children with autism spectrum disorder, Paladyn, Journal Of Behavioral Robotics, 2017, 8(1), 18-38, DOI:10.1515/pjbr-2017-0002 